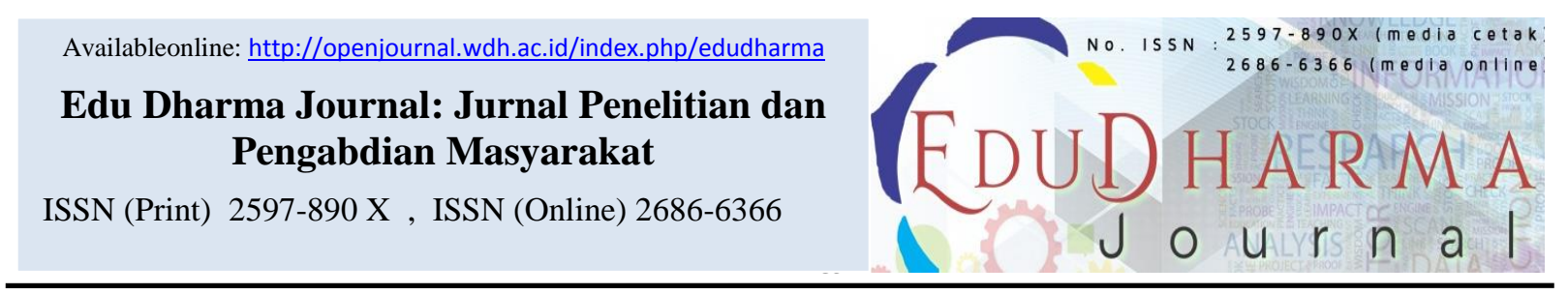

\title{
KORELASI KARAKTERISTIK RESPONDEN DENGAN KEPUASAN PERNIKAHAN PADA ISTRI YANG MELAKUKAN PERNIKAHAN DINI DI KECAMATAN PAGEDANGAN
}

\author{
${ }^{1}$ Sri Haryanto, ${ }^{2}$ Andini Restu Marsiwi, ${ }^{3}$ Evi Nurnaini, ${ }^{4}$ Syahrani Widya Meifani \\ ${ }^{1,2}$ Dosen Program Studi S1 Keperawatan STIKesWidya Dharma Husada Tangerang,, Jalan Pajajaran No.1 Pamulang Barat, Tangerang \\ Selatan, Banten \\ ${ }^{3,4}$ Mahasiswa Program Studi S1 Keperawatan STIKesWidya Dharma HusadaTangerang, Jalan Pajajaran No.1 Pamulang Barat, Tangerang \\ Selatan, Banten
}

\begin{tabular}{|c|c|}
\hline ARTICLE INFORMATION & $A B S T R A C T$ \\
\hline $\begin{array}{l}\text { *Corresponding Author } \\
\text { Sri Haryanto } \\
\text { E-mail: sriharyantokusnarno@gmail.com }\end{array}$ & $\begin{array}{l}\text { Marriage satisfaction is a feeling of happiness, satisfaction, and } \\
\text { happiness experienced by a married couple in connection with } \\
\text { aspects of marriage. The purpose of this study was to determine } \\
\text { whether there is a relationship between age, education level and } \\
\text { work status with the satisfaction of marriage to wives who have }\end{array}$ \\
\hline $\begin{array}{l}\text { Keywords: } \\
\text { Age_1 } \\
\text { Education Level_2 } \\
\text { Working Status_3 } \\
\text { Marriage Satisfaction_4 }\end{array}$ & $\begin{array}{l}\text { This research used descriptive analytic with cross sectional } \\
\text { method with } 43 \text { samples. Data collected by distributing } \\
\text { questionnaires. Data analysis used Chi Square test. The results } \\
\text { of the analysis found that there is no connection between age and } \\
\text { marriage satisfaction ( } \text {-value }=0.415 \text { ), there is a conncetion } \\
\text { between education level and marriage satisfaction ( } p \text {-value = } \\
\text { 0.005), and there is a connection between work status and } \\
\text { marriage satisfaction ( } p \text {-value = 0.002). Conclusion: there is a } \\
\text { significant connection between age and marriage satisfaction, } \\
\text { education level with marriage satisfaction, and status of work } \\
\text { with marriage satisfaction. Suggestion: It is hoped that a young } \\
\text { wife before marriage can continue to explore information about } \\
\text { the effects of a early marriage so that the satisfaction of her } \\
\text { marriage cannot have a negative impact on her domestic life. } \\
\text { Even so getting married at an early age is risky. } \\
\text { Keywords: Age, Education Level, Working Status, Marriage } \\
\text { Satisfaction. }\end{array}$ \\
\hline $\begin{array}{l}\text { Kata Kunci: } \\
\text { Usia_1 } \\
\text { Tingkat Pendidikan_2 } \\
\text { Status Bekerja_3 } \\
\text { Kepuasan Pernikahan_4 }\end{array}$ & $\begin{array}{l}\text { A B S T R A K } \\
\text { Kepuasan perkawinan adalah perasaan Bahagia, puas, dan } \\
\text { senang yang di alami oleh pasangan suami istri sehubungan } \\
\text { dengan aspek-aspek dalam perkawinan.Tujuan Penelitian ini } \\
\text { adalah untuk mengetahui ada tidaknya hubungan antara usia, } \\
\text { tingkat Pendidikan dan status bekerja dengan kepuasan } \\
\text { pernikahan pada istri yang melakukan pernikahan dini di } \\
\text { Kecamatan Pagedangan Kabupaten Tangerang. Metode } \\
\text { penelitianini adalah deskriptif analitik dengan metode cross } \\
\text { sectional dengan jumlah sampel sebanyak } 43 \text { sampel. } \\
\text { Pengumpulan data dilakukan dengan penyebaran kuesioner. }\end{array}$ \\
\hline
\end{tabular}




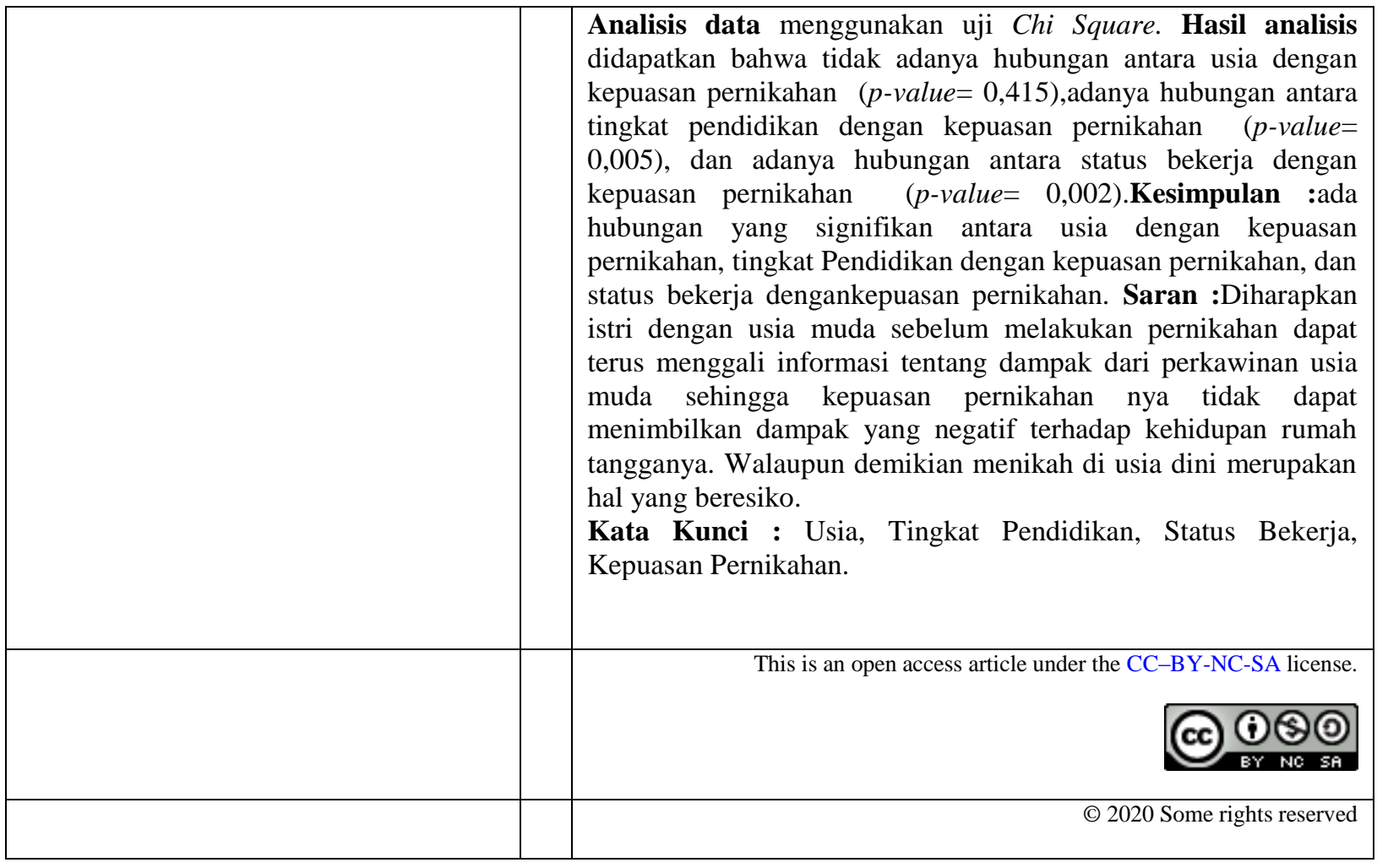




\section{PENDAHULUAN}

Menurut World Health

Organization, sebanyak 14,2 juta anak perempuan setiap tahunnya menikah pada usia muda. Pada tahun 2016 ada sekitar 142 anak perempuan yang melakukan pernikahan sebelum waktunya. Indonesia menempati peringkat ke-37 dengan jumlah pernikahan dibawah umur paling tinggi kedua di kawasan Asia Tenggara. Tentu bukan hal yang membanggakan karena ini mempengaruhi tingkat kepadatan penduduk karena berpotensi terhadap tingkat kelahiran yang tinggi pula. Data dari (Badan Pusat Statistik, 2017).

Provinsi dengan persentase pernikahan dini dibawah 15 tahun dengan posisi paling tinggi di Indonesia adalah Kalimantan Selatan (9\%), dan Banten 6,5\% Badan Kependudukan dan Keluarga Bencana Nasional menegaskan bahwa Indonesia merupakan negara dengan jumlah persentase pernikahan di usia dini tinggi di dunia. Perempuan muda di Indonesia dengan usia 10-14 sebanyak $0,2 \%$ atau lebih dari 22.000 sudah menikah. Jumlah remaja di Indonesia yang sudah memiliki anak cukup tinggi yaitu 1000 remaja. (Muntamah, dkk, 2019).

Perubahan-perubahan ini mempunyai implikasi pada remaja agar mereka dapat memahami hal-hal yang menjadi faktor resiko kesehatan, remaja dituntut untuk dapat berfikir ke depan dan menilai sisi positif dan negatif dalam membina hubungan rumah tangga yang harmonis. Adapun dampak negatif dari pernikahan dini, yaitu pertama dalam segi kesehatan ketidaksiapannya sistem organ reproduksi wanita yang mengakibatkan kehamilan yang beresiko apabila mengalami kehamilan. Kedua dalam segi psikologis, usia remaja yaitu usia yang tengah mencari jati diri sehingga dalam segi mental pun belum siap. Ketiga dalam segi sosial, masa remaja membutuhkan pergaulan dan teman sebaya maka hal ini kehilangan kesempatan, begitupun dengan putusnya sekolah maka wanita yang kurang pendidikan dan tidak siap menjalankan perannya sebagai ibu (Kemenkes RI, 2015).

Pada kasus tingginya angka perceraian di Indonesia, Pengadilan Agama Ponorogo (PA) mencatat angka perceraian hingga September 2019 mencapai 1.633 kasus. Perceraian tersebut dilatar belakangi masalah ekonomi selain karena perselingkuhan. Humas PA Ponorogo Misnan Maulana menyebutkan, PA Ponorogo mencatat hingga September 2019, terdapat 1.777 perkara pernikahan dengan 1.633 merupakan perceraian. Dari angka perceraian itu sebanyak 1.162 cerai 
gugat diajukan istri. Sedangkan sebanyak 471 perkara cerai talak diajukan suami. Faktor yang mempengaruhi perceraian karena adanya ketidakpuasan pernikahan dalam suatu hubungan.

Dari hasil wawancara dan pemberian koesioner pada di 5 istri pasangan didapatkan hasil 3 responden mengatakan mereka menikah atas dasar mengikuti keinginan orang tua dengan koesioner kepuasan pernikahannya rendah dan 2 responden mengatakan menikah atas dasar keinginan dari diri sendiri dengan koesioner kepuasan pernikahan sedang.

\section{METODE}

Desain dalam penelitian ini menggunakan jenis penelitian Deskriptif analitik dengan pendekatan Cross Sectional.Penelitian ini dilaksanakan di Kecamatan Pagedangan Kabupaten Tangerang. Penelitian ini di laksanakan 14 s/d 20 Juni 2020. Populasi dalam penelitian ini adalah istri yang melakukan pernikahan dini di Kecamatan Pagedangan Kabupaten Tangerang. Pengambilan sampel menggunakan total sampling. Teknik pengumpulan data kuantitatif untuk data primer pada penelitianini dengan penyebaran koesioner. Variabel independen pada penelitian inia dalah Usia, Tingkat Pendidikan, dan Status
Bekerja. Adapun variable dependennya adalah Kepuasan Pernikahan.

\section{HASIL}

\section{Analisa Univariat}

a. Data Karakteristik Responden

Tabel 1. Tendensi Central Berdasarkan

Usia Istri yang Melakukan

Pernikahan Dini di Kecamatan Pagedangan

\begin{tabular}{|c|c|c|}
\hline Usia & & 43 \\
\hline \multirow[t]{2}{*}{$\mathrm{N}$} & $\mathrm{N}$ & 43 \\
\hline & $\mathrm{N}$ & 0 \\
\hline Mean & & 16.77 \\
\hline Median & & 16.78 \\
\hline Mode & & 17 \\
\hline Std. Deviation & & 1.306 \\
\hline Minimum & & 14 \\
\hline Maximum & & 19 \\
\hline
\end{tabular}

Karakteristik responden berdasarkan tendesi central berdasarkan usia istri yang melakukan pernikahan dini di Kecamatan Pagedangan di dapatkan hasil nilai terkecil yaitu 14 artinya yang berumur paling rendah di dalam penelitian ini yaitu 14 tahun, niai tertinggi 19 artinya yang berumur paling tua 19 tahun, dan mean yaitu 16,77 yang artinya rerata usia responden pada penelitian ini adalah 16 tahun. 
b. Jenjang Pendidikan

Tabel 2. Distribusi Frekuensi Berdasarkan Pendidikan di Kecamatan Pagedangan

\begin{tabular}{ccc}
\hline \multirow{2}{*}{$\begin{array}{c}\text { Tingkat } \\
\text { Pendidikan }\end{array}$} & \multicolumn{2}{c}{ Total } \\
\cline { 2 - 3 } & Frekuensi & $\begin{array}{c}\text { Persentase } \\
(\%)\end{array}$ \\
\hline Tidaksekolah & 4 & Tidaksekolah \\
\hline SD & 6 & SD \\
\hline SMP & 28 & SMP \\
\hline SMA & 5 & SMA \\
\hline TOTAL & 43 & TOTAL \\
\hline
\end{tabular}

Sumber : (data primer, 2020)

Karakteristik responden berdasarkan tingkat Pendidikan istri yang melakukan pernikahan dini di Kecamatan Pagedangan. Hampir setengahnya responden berjumlah 28 responden berpendidikan SMP $(67,4 \%)$, dan sebagian kecil berjumlah 4 responden berpendidikan Tidak Sekolah(7,0\%). c. Status Bekerja

Tabel 3. Distribusi Frekuensi Berdasarkan Istri yang bekerja di Kecamatan Pagedangan

\begin{tabular}{lll}
\hline Status Bekerja & \multicolumn{2}{c}{ Total } \\
\cline { 2 - 3 } & Frekuensi & $\begin{array}{l}\text { Persentase } \\
(\%)\end{array}$ \\
\hline Bekerja & 12 & $27,9 \%$ \\
\hline TidakBekerja & 31 & $72,1 \%$ \\
\hline TOTAL & 43 & \\
\hline Sumber : (data primer, 2020)
\end{tabular}

Sumber : (data primer, 2020)

Karakteristik responden berdasarkan status bekerja bahwa status bekerja istri yang melakukan pernikahan di Kecamatan Pagedangan responden yang tidak bekerja yaitu 31 responden $(72,1 \%)$, dan sebagian kecil 12 responden bekerja $(27,9 \%)$.

Kepuasan Pernikahan

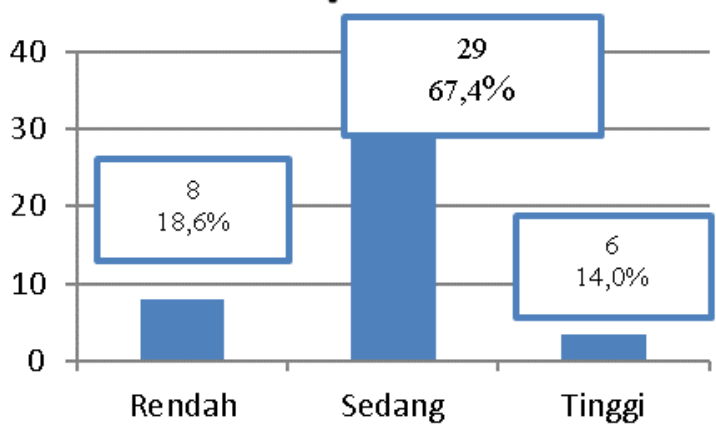

Gambar 1. Kepuasan Pernikahan

Berdasarkan Diagram 1. Distribusi

Frekuensi Kepuasan Penikahan di

Kecamatan Pagedangan Kabupaten

Tangerang menunjukan bahwa lebih dari
Kepuasan Pernikahan

setengahnya 29 responden $(67,4 \%)$ memiliki kepuasan pernikahan sedang, 8 responden $(18,6 \%)$,dan Sebagian kecil 6 responden $(14,0 \%)$ memiliki kepuasan pernikahan tinggi. 


\section{Analisa Bivariat}

Tabel 4. Hasil Crosstabulation Usia dengan Kepuasan Pernikahan

\begin{tabular}{|c|c|c|c|c|c|c|c|c|c|}
\hline \multicolumn{10}{|c|}{ Usia } \\
\hline \multirow[t]{3}{*}{ Usia } & \multicolumn{6}{|c|}{ KepuasanPernikahan } & & & \multirow{3}{*}{ P-Value } \\
\hline & \multicolumn{2}{|c|}{ Rendah } & \multicolumn{2}{|c|}{ Sedang } & \multicolumn{2}{|c|}{ Tinggi } & \multicolumn{2}{|c|}{ Total } & \\
\hline & $\mathrm{n}$ & $\%$ & $\mathrm{n}$ & $\%$ & $\mathrm{~N}$ & $\%$ & $\mathrm{~N}$ & $\%$ & \\
\hline 14 Tahun & 0 & 0,0 & 1 & 2,3 & 1 & 2,3 & 2 & 4,7 & 0,415 \\
\hline 15 Tahun & 0 & 0,0 & 3 & 7,0 & 2 & 4,7 & 5 & 11,6 & \\
\hline 16 Tahun & 3 & 7,0 & 6 & 14,0 & 2 & 4,7 & 11 & 25,6 & \\
\hline 17 Tahun & 1 & 2,3 & 11 & 25,6 & 0 & 0,0 & 12 & 27,9 & \\
\hline 18 Tahun & 1 & 2,3 & 5 & 11,6 & 3 & 7,0 & 9 & 20,9 & \\
\hline 19 Tahun & 0 & 0,0 & 3 & 7,0 & 1 & 2,3 & 4 & 9,3 & \\
\hline Total & 5 & 11,6 & 29 & 67,4 & 9 & 20,9 & 43 & 100,0 & \\
\hline
\end{tabular}

Berdasarkan tabel 4, hubungan antara usia dengan kepuasan pernikahan pada istri yang melakukan pernikahan dini di Kecamatan Pagedangan berjumlah 43 responden dengan usia 14 tahun serta tingkat kepuasan pernikahan tinggi sebanyak 1 responden $(2,3 \%)$, dan rendah sebanyak 0 responden $(0,0 \%)$. Usia 15 tahun serta tingkat kepuasan tinggi sebanyak 2 responden $(4,7 \%)$ dan Rendah sebanyak 0 responden $(0,0 \%)$. Usia 16 tahun serta tingkat kepuasan tinggi sebanyak 2 responden $(4,7 \%)$, Sedang sebanyak 11 responden $(25,6 \%)$ dan Rendah sebanyak 3 responden $(7,0 \%)$. Usia 17 tahun serta tingkat kepuasan tinggi sebanyak 0 responden $(0,0 \%)$, Sedang sebanyak 11 responden $(25,6 \%)$ dan Rendah sebanyak 1 responden $(2,3 \%)$. Usia 18 tahun serta tingkat kepuasan tinggi sebanyak 3 responden $(7,0 \%)$, Sedang sebanyak 5 responden $(11,6 \%)$ dan Rendah sebanyak 1 responden $(2,3 \%)$. Usia 19 tahun serta tingkat kepuasan tinggi sebanyak 4 responden $(9,3 \%)$ dan Rendah sebanyak 0 responden $(0,0 \%)$.

Tabel 5. Hasil Crosstabulation Tingkat Pendidikan dengan Kepuasan Pernikahan

\begin{tabular}{|c|c|c|c|c|c|c|c|c|c|}
\hline \multicolumn{10}{|c|}{ Pendidikan } \\
\hline \multirow[t]{3}{*}{ Pendidikan } & \multicolumn{6}{|c|}{ KepuasanPernikahan } & \multirow{2}{*}{\multicolumn{2}{|c|}{ Total }} & \multirow{3}{*}{ P-Value } \\
\hline & \multicolumn{2}{|c|}{ Rendah } & \multicolumn{2}{|c|}{ Sedang } & \multicolumn{2}{|c|}{ Tinggi } & & & \\
\hline & $\mathrm{n}$ & $\%$ & $\mathrm{n}$ & $\%$ & $\mathrm{~N}$ & $\%$ & $\mathrm{~N}$ & $\%$ & \\
\hline Tidaksekolah & 2 & 4,7 & 2 & 4,7 & 0 & 0,0 & 4 & 9,3 & 0,005 \\
\hline SD & 2 & 4,7 & 2 & 4,7 & 2 & 4,7 & 6 & 14,0 & \\
\hline SMP & 4 & 9,3 & 23 & 53,5 & 1 & 2,3 & 28 & 65,1 & \\
\hline SMA & 0 & 0,0 & 2 & 4,7 & 3 & 7,0 & 5 & 11,6 & \\
\hline Total & 8 & 18,6 & 29 & 27,4 & 6 & 14,0 & 43 & 100.0 & \\
\hline
\end{tabular}


Berdasarkan tabel 5. hubungan antara Tingkat Pendidikan dengan kepuasan pernikahan pada istri yang melakukan pernikahan dini di Kecamatan Pagedangan berjumlah 43 responden dengan tingkat Pendidikan Tidak sekolah serta tingkat kepuasan pernikahan tinggi sebanyak 0 responden $(0,0 \%)$, Sedang sebanyak 2 responden $(4,7 \%)$ dan rendah sebanyak 2 responden $(4,7 \%)$. Tingkat Pendidikan SD serta tingkat kepuasan tinggi sebanyak 2 responden $(4,7 \%)$, Sedang sebanyak 2 responden $(4,7 \%)$ dan Rendah sebanyak 2 responden $(4,7 \%)$. Tingkat Pendidikan SMP serta tingkat kepuasan tinggi sebanyak 1 responden $(2,3 \%)$, Sedang sebanyak 23 responden $(53,5 \%)$ dan Rendah sebanyak 4 responden $(9,3 \%)$. Tingkat Pendidikan SMA serta tingkat kepuasan tinggi sebanyak 3 responden $(7,0 \%)$, Sedang sebanyak 2 responden $(4,7 \%)$ dan Rendah sebanyak 0 responden $(0,0 \%)$.

Tabel 6. Crosstabulation Status Bekerja dengan Kepuasan Pernikahan

\begin{tabular}{|c|c|c|c|c|c|c|c|c|c|}
\hline \multicolumn{10}{|c|}{ Status Bekerja } \\
\hline \multirow[t]{3}{*}{ Status bekerja } & \multicolumn{6}{|c|}{ KepuasanPernikahan } & \multirow{2}{*}{\multicolumn{2}{|c|}{ Total }} & \multirow{3}{*}{ P-Value } \\
\hline & \multicolumn{2}{|c|}{ Rendah } & \multicolumn{2}{|c|}{ Sedang } & \multicolumn{2}{|c|}{ Tinggi } & & & \\
\hline & $\mathrm{n}$ & $\%$ & $\mathrm{n}$ & $\%$ & $\mathrm{~N}$ & $\%$ & $\mathrm{~N}$ & $\%$ & \\
\hline Bekerja & 0 & 0,0 & 7 & 16,3 & 5 & 11,6 & 12 & 27,9 & 0,002 \\
\hline Tidakbekerja & 8 & 18,6 & 22 & 51,2 & 1 & 2,3 & 31 & 72,1 & \\
\hline Total & 8 & 16,6 & 29 & 67,4 & 6 & 14,0 & 43 & 100.0 & \\
\hline
\end{tabular}

Berdasarkan tabel 6, hubungan antara Status Bekerja dengan kepuasan pernikahan pada istri yang melakukan pernikahan dini di Kecamatan Pagedangan berjumlah 43 responden dengan status bekerja responden bekerja serta tingkat kepuasan pernikahan tinggi sebanyak 5 responden $(11,6 \%)$, Sedang sebanyak 7 responden $(16,3 \%)$ dan rendah sebanyak 0 responden $(0,0 \%)$. Status bekerja responden yang tidak bekerja serta tingkat kepuasan tinggi sebanyak 1 responden (2,3\%), Sedang sebanyak 22 responden $(51,2 \%)$ dan Rendah sebanyak 8 responden $(18,6 \%)$.

mempengaruhi pernikahan usia dini pada remaja wanita di kelurahan Kelayan Timur

\section{Analisa Univariat}

a. Usia

Berdasarkan penelitian oleh Warjiman (2016) dengan judul "faktor-faktor yang 
Kecamatan Banjarmasin Selatan Kota Banjarmasin" yang menunjukan bahwa sebagian besar responden berumur 18-20 tahun atau dengan jumlah $(66,7 \%)$.

Menurut peneliti responden usia di bawah 20 tahun adalah usia yang masih mencarari jati diri yang masih membutuhkan untuk bersosialisasi dengan teman sebaya dan social lingkungannya. Dalam segi kesehatan pun usia remaja memiliki resiko kesehatan apabila mengalami kehamilan dan persalinan. Mental untuk hamil pun remaja masih belum bias menerima karena keadaan belum siap mental untuk hamil, namun karena keadaan ia terpaksa menerima kehamilan dengan bersiko.

\section{b. Tingkat Pendidikan}

Hasil penelitian ini sesuai dengan penelitian Warjiman,(2016) dengan judul "faktor-faktor yang mempengaruhi pernikahan usia dini pada remaja wanita di Kelurahan Kelayan Timur Kecamatan Banjarmasin Selatan Kota Banjarmasin" menunjukkan bahwa pendidikan paling terbanyak berada tingkat pendidikan SMP/sederajat dengan jumlah 12 orang $(40 \%)$.

\section{c. Status Bekerja}

Hasil penelitian Kurniawati dan Nurrochmah (2017) berjudul "Hubungan antar tingkat Pendidikan, status pekerjaan dan tingkat pendapatan dengan usia perkawinan pertama wanita di kelurahan kota lama kecamatan kedung kandang kota malang". Menunjukan bahwa status pekerjaan tidak bekerja 84 responden $(67,2 \%)$, dan yang bekerja 41 responden $(32,8)$

\section{d. KepuasanPernikahan}

Berdasarkan penelitian yang dilakukan oleh Sudarto (2016) berjudul "Studi Deskriptif Kepuasan Perkawinan pada Perempuan yang Menikah Dini di Surabaya" menunjukkan bahwa pernikahan pada usia 16-19 tahun ditemukan kepuasan perkawinan 75 perempuan yang menikah pada usia dini dibagi dalam empat kelompok (rendah $(\mathrm{N}=3),(\mathrm{N}=8)$, tinggi $(\mathrm{N}=24)$, dan sangat tinggi $(\mathrm{N}=40)$.

2. Analisa Bivariat

a. Hubungan antara Usia dengan kepuasan pernikahan pada istri yang melakukan pernikahan dini di Kecamatan Pagedangan Kabupaten Tangerang.

Sesuai dengan penelitian oleh Mutia dan Thobagus (2018) dengan judul "Hubungan kepercayaan dengan kepuasan perkawinan di Yogyakarta" diperoleh hasil nilai pvalue $=0,666(\mathrm{p}>0,05)$ yang artinya $\mathrm{Ha}$ ditolak H0 diterima, maka dapat disimpulkan tidak ada hubungan usia dengan kepuasan pernikahan pada istri. 
Menurut asusmsi peneliti usia remaja tidak mempengaruhi kepuasan pernikahan karena usia remaja masih labil belum bias memikir matang sehungga dapat dipengaruhi oleh factor lain. Orang-orang yang menikah mudah beresiko tinggi mengalami ketidak stabilan pernikahan di bandingkan mereka yang menikah di usia yang lebih tua. Usia memiliki hubungan negative dengan keberhasilan sebuah pernikahan karena pada saat menikah di usia relative masih muda, kehamilan pranikah, pendeknya masa perkenalan sebelum menikah, dan ketidakmampuan menyesuaikan diri denganr endahnya latar belakang social ekonomi.

b. Hubungan antara Pendidikan dengan kepuasan pernikahan pada istri yang melakukan pernikahan dini di Kecamatan Pagedangan Kabupaten Tangerang.

Penelitian ini sejalan dengan penelitian Melani, Sunarti, dan Krisnatuti (2015) dengan judul "Faktor Demografi, Konflik Kerja, Dan Kepuasan Pernikahan" didapat nilai $\mathrm{p}$-value $=0,001(\mathrm{p}<0,05)$ yang artinya Ha diterima $\mathrm{HO}$ ditolak, sehingga dapat disimpulkan terdapat hubungan status Pendidikan dengan kepuasan pernikahan.

Peneliti berasumsi adanya hubungan Pendidikan dengan kepuasan pernikahan disebabkan karena tingkat Pendidikan umumnya akan meningkat sesuai dengan bertambahnya usia. Kepuasan pernikahan terdapat pada jenjang Pendidikan terakhir yaitu SMP. Hal ini tidak sesuai dengan teori yang menyebutkan bahwa semakin tinggi jenjang Pendidikan seseorang semakin tinggi pula tingkat kepuasan perkawinan. Penelitian oleh Istiqomah dan Mukhlis (2015) dengan subjek pendidikan $\mathrm{SD}, \mathrm{SMP}, \mathrm{SMA}, \mathrm{S} 1, \mathrm{~S} 2$ menunjukan kepuasan pada pernikahan paling tinggi SMA.

c. Hubungan antara Status Bekerja dengan kepuasan pernikahan pada istri yang melakukan pernikahan dini di Kecamatan Pagedangan Kabupaten Tangerang.

Penelitian ini tidak sejalan dengan penelituan Novia Rahma Widi K. (2018) dengan judul "Perbedaan Kepuasan Pernikahan Ditinjau dari Status Istri" didapat nilai $\mathrm{p}$-value $=1,629(\mathrm{p}<0,05)$ yang artinya Ha ditolak H0 diterima, maka disimpulkan terdapat tidak ada hubungan status istri dengan kepuasan pernikahan.

\section{KESIMPULAN}

1. Gambaran karateristik responden usia istri yang melakukan pernikahan dini di Kecamatan Pagedangan dengan Hasil analisia univariat berdasarkan umur di dapatkan bahwa rentang usia responden penelitian ini adalah 14 
sampai 19 tahun dan rata-rata usia responden 16 tahun.

2. Gambaran karakteristik Tingkat pendidikan istri yang melakukan pernikahan dini di Kecamatan Pagedangan yaitu hamper setengahnya responden berjumlah 28 responden berpendidikan SMP $(67,4 \%)$, dan sebagian kecil berjumlah 4 responden berpendidikan Tidak Sekolah(7,0\%).

3. Gambaran Karakteristik responden dengan status bekerja bahwa pekerjaan Istri yang melakukan pernikahan dini di Kecamatan Pagedangan sebagaian besar responden yang tidak bekerja yaitu 31 responden(72,1\%), sebagian kecil 12 responden bekerja $(27,9 \%)$.

4. Gambaran kepuasan pernikahan bahwa lebih dari setengahnya 29 responden $(67,4 \%)$ memiliki kepuasan pernikahan sedang, 8 responden $(18,6 \%)$ memiliki kepuasan pernikahan rendah, dan 6 responden $(14,0 \%)$ memiliki kepuasan pernikahan rendah.

5. Tidak adanya hubungan yang bermakna antara Usia dengankepuasan pernikahan di Kecamatan Pagedangan Kabupaten Tangerang menunjukan bahwa nilai $(\mathrm{p}$-value $=0,415)$ maka disimpulkan $\mathrm{Ha}$ ditolak dan $\mathrm{H} 0$ diterima.
6. Ada hubungan yang bermakna antara Pendidikan dengan kepuasan pernikahan di Kecamatan Pagedangan Kabupaten Tangerang menunjukan bahwa nilai $(\mathrm{p}$-value $=0,005)$ sehingga dapat disimpulkan bahwa Ha diterima dan H0 ditolak.

7. Ada hubungan yang bermakna antara Status Bekerja dengan kepuasan pernikahan di Kecamatan Pagedangan Kabupaten Tangerang menunjukan bahwa nilai $(\mathrm{p}$-value $=0,002)$ maka dapat diambil kesimpulan bahwa $\mathrm{Ha}$ diterima dan $\mathrm{H} 0$ ditolak.

\section{DAFTAR PUSTAKA}

Abdul, Rahman. 1986. Himpunan Peraturan Undang-Undang Tentang Perkawinan. Jakarta :Akademika Presindi.

Asak, P, dan Wiliani, A. 2019. Peran Kecerdasam Emosi Terhadap Kepuasan Pernikahan Pada Remaja Yang Menikah Muda Di Bali. Jurnal PsikologiVol.6, No.2, 337-346

Kementrian kesehatan RI. 2016. Profil Kesehatan Indonesia Tahun 2015. Jakarta : Kementrian Kesehatan RI.

Melani, F., Sunarti, E., dan Krisnatuti. 2015.Faktor Demografi, Konflik Kerja, Dan Kepuasan Pernikahan Jurna lilmiah kel.\&kons:133-142.

Muntamalah, Latifatul., Latifiano, Dian., dan Arifin, Ridwan. 2019. Pernikahan Dini Di Indonesia: Faktor Dan Peran 
Pemerintah. Jurnal Hukum, 2 (1) : 2 3.

Putri, Soraiya., dkk. 2016. Kelekatan Dan Kepuasan Pernikahan Pada Dewasa Awal Di Kota Banda Aceh. JurnalPsikologi. 36-42.

Sudarto, Angela. 2014. Studi Deskriptif Perkawinan Pada Perempuan Yang Menikah Dini. Jurnal Ilmiah Psikolog.

Suru, N. 2014. Ini Alasan Perceraian Tertinggi di Indonesia. Dikutip dari http://health.liputan6.com.

Wiliani, Ari., dan Asak ,Pradyadew. 2019. Peran kecerdasan emosi terhadap kepuasan pernikahan pada remaja yang menikah muda. Jurna lPsikologi Udayana. Hal : 338.

Wisono, Mulyadi., dan Anjar, S. C. N. 2017. Akibat Hukum Penepatan Dispensasi Perkawinan Anak di Bawah Umur (Studi Kasus di Pengadilan Agama Pacitan). Privat law. 5(2) : 1-70.

Zahra, S., dan Riselligia, C. 2016. Hubungan Antara Kepuasan Pernikahan Dengan Spiritualitas Pada IstriBekerja Yang Berada Dalam Tahap Pernikahan Families With School Children.Jurnal Psikogenesis, 4(2). 